Roger Williams University

DOCS@RWU

5-18-2012

\title{
The Effect of Age and Expression of Affect on Jurors' Perceptions of Child Witnesses
}

Carly W. Hanks

Roger Williams University, chanks309@g.rwu.edu

Follow this and additional works at: https://docs.rwu.edu/psych_thesis

Part of the Psychology Commons

\section{Recommended Citation}

Hanks, Carly W., "The Effect of Age and Expression of Affect on Jurors' Perceptions of Child Witnesses" (2012). Psychology Theses. 15.

https://docs.rwu.edu/psych_thesis/15

This Thesis is brought to you for free and open access by the Arts and Sciences Theses at DOCS@RWU. It has been accepted for inclusion in Psychology Theses by an authorized administrator of DOCS@RWU. For more information, please contact mwu@rwu.edu. 
Running head: EFFECT OF AGE AND EXPRESSION OF AFFECT

The Effect of Age and Expression of Affect on Jurors' Perceptions of Child Witnesses

Carly W. Hanks

Master of Arts

Forensic Psychology

Feinstein College of Arts and Sciences

Roger Williams University

May 2012 
EFFECT OF AGE AND EXPRESSION OF AFFECT

ii

ROGER WILLIAMS UNIVERSITY

MASTERS PROGRAM IN FORENSIC PSYCHOLOGY

THESIS PROJECT FORM

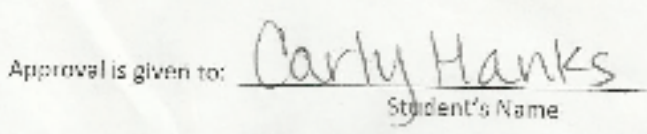

$$
\text { Date: } 2-8-11
$$

a candidate for degree of Waster of Arts in FORFMSIC PSYCHOLOGY, to conduct the foil owing research project: Juror Perceptions of child Witness credibility

1. Composition of Master's Thesis Committee:

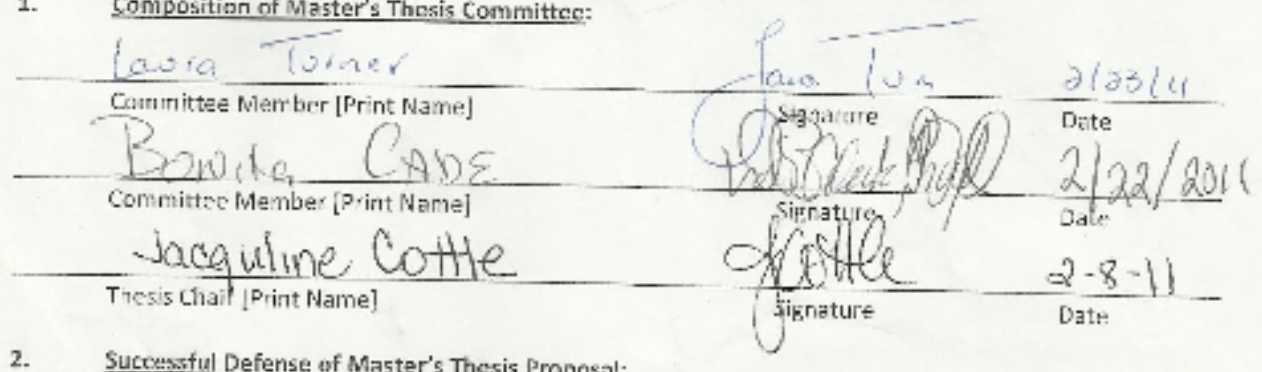

2. Successful Defense of Master's Thesis Proposal:

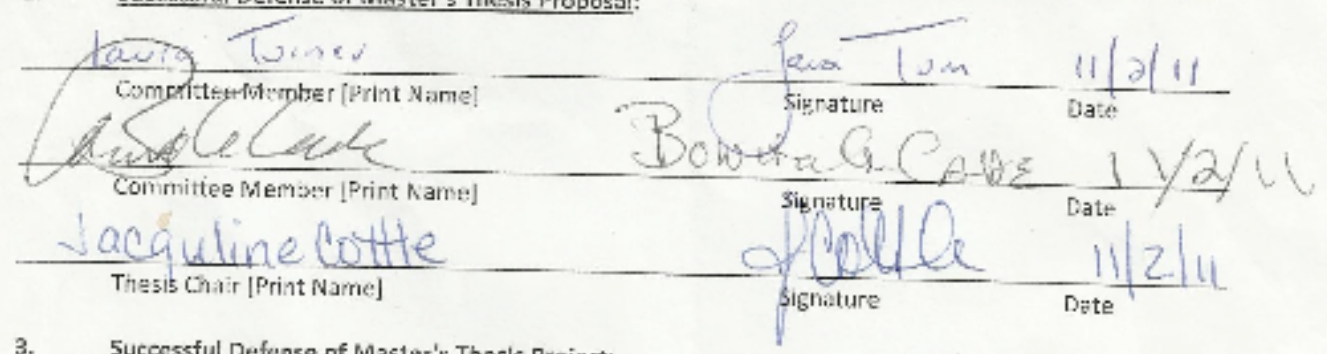

3. Successful Defense of Master's Thesis Project:

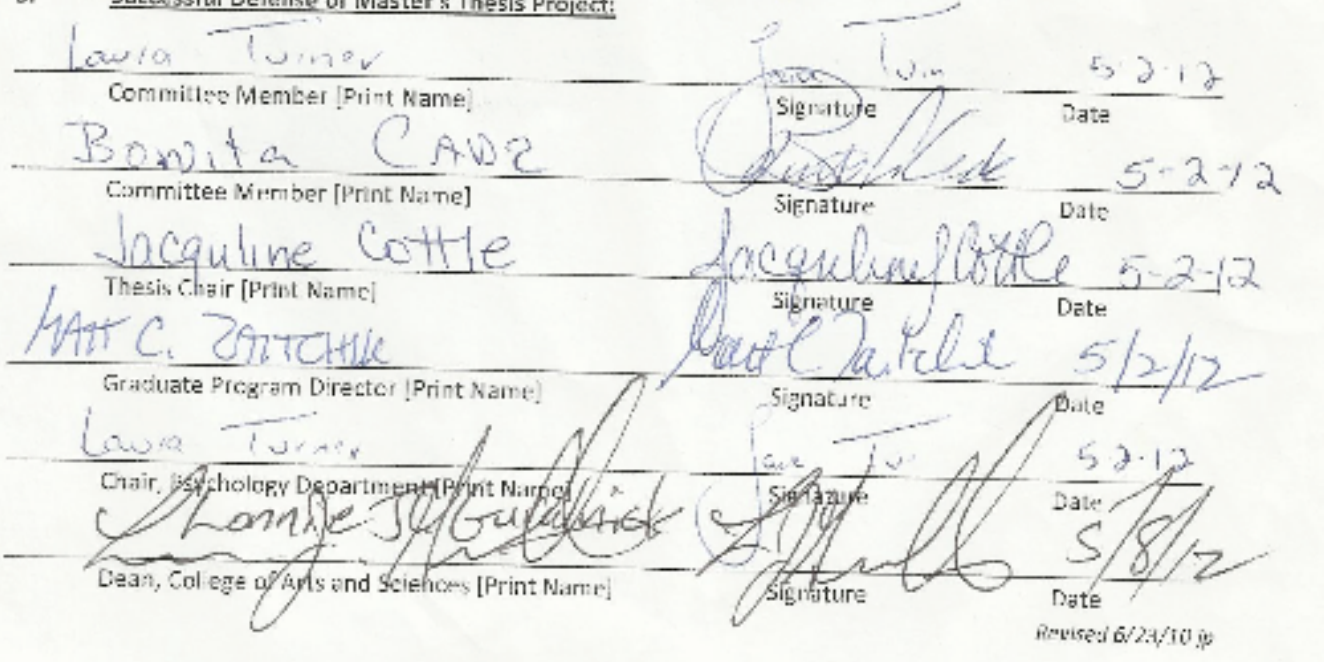




\section{Acknowledgments}

A special thank you to my committee chair, Dr. Jacquline Cottle, my committee members, Dr. Bonita Cade and Dr. Laura Turner, and to my research assistant, Laura Vargas. Thank you for your time and advice. 


\begin{abstract}
A child witness's testimony may be an invaluable piece of evidence; therefore, it is essential to study the circumstances under which jurors perceive children as credible witnesses. The current study examined affect while testifying on perceptions of the child's credibility, the amount of blame attributed to the witness, and case verdict decisions. A case scenario about an aggravated robbery of a girl who was either 6- or 13-years-old and who either cried or remained calm while testifying was read by 186 undergraduate participants. No age effects were found, possibly due to the non-sexual nature of the case. No effects for expression of affect were found, possibly because participants need to view affective reactions for them to be influential.
\end{abstract}

Keywords: child witness, age, affect, blame, credibility 
EFFECT OF AGE AND EXPRESSION OF AFFECT

The Effect of Age and Expression of Affect on Jurors' Perceptions of Child Witnesses

A child witness's testimony can be an invaluable piece of evidence in cases with a limited number of eyewitnesses or where the child is the only witness (e.g., sexual abuse cases). When such cases go to trial, the child often provides the key testimony and the success of the case will depend on the extent to which the child is believed. The Supreme Court in Pennsylvania v. Ritchie (1987) recognized that a child witness's testimony is important as possible evidence of an alleged perpetrator's wrongdoing.

Whereas the courts have established guidelines to ensure that a child is competent to testify in open court, potentially in front of a jury (Melton, 1981), other factors may influence whether the trier of fact finds the child's testimony believable. Thus, it is essential to study the circumstances under which jurors perceive children as credible witnesses. Research has examined how the stereotypes jurors have about children as witnesses affects their verdict decisions and their judgments of the child's credibility. These stereotypes may take into account the child's age, the type of case in which the child is involved, and how children present themselves while testifying. All of these factors may also contribute to the amount of blame jurors attribute to the child for his or her victimization and, ultimately, the case outcome.

\section{Stereotypes About Child Witnesses}

Research has shown that children are able to provide detailed, accurate descriptions of events as long as questions are posed in a direct manner and in language understandable to the child (Melton, 1981). However, even though children are fully capable of providing accurate testimony, jurors often base their assessments of a child witness's credibility on pre-existing stereotypes about children and whether the child's behavior while testifying matches those existing stereotypes. Consequently, both laypersons and professionals may view children as less 
trustworthy, inexpert, suggestible, and unreliable, and thereby lessening their persuasive power as witnesses (Leippe \& Romanczyk, 1989; Ross, Dunning, Toglia, \& Ceci, 1990). However, even when negative assumptions are made about a child's memory abilities, so long as the child's message fits the jurors' stereotypes of how a reliable child speaks and behaves, the message of the child's testimony may still be accepted and believed. Thus, a child witness can be less, equally, or more believed than an adult witness, depending on the extent to which the child behaved consistently or inconsistently with the stereotype held by the observer (Leippe \& Romanczyk, 1989).

On the other hand, these stereotypes may also make jurors more sensitive and unforgiving of a child's inconsistent testimony (Ross, et al., 1990). Ross et al. (1990) examined mock-jurors' general beliefs about child witnesses' abilities. They found that mock-jurors reported beliefs that child witnesses were less likely to give accurate testimony and were more susceptible to suggestion than adult witnesses. However, after viewing a child witness testify, they found the child more believable than the adult witnesses. The contradiction in these findings may be due to the assimilation effect, when social judgments are based on information that either confirms or violates preconceived stereotypes (Ross et al., 1990). The mock-jurors may have attributed greater believability to the child's testimony because the child presented as more mature, acting older than his or her true age, violating their stereotypes of child witnesses. If a person expected to see a specific characteristic (e.g. inconsistency in the testimony) in a witness, and the witness's behavior did not conform to the expectation or was not ambiguous enough to be interpreted as conforming, the person viewed the witness as more credible. Accordingly, if a child witness acted very childish, he or she conformed to the stereotype for children and was then perceived as less credible, but if he or she acted more mature and adult- 
like, he or she appeared more credible (Ross et al., 1990). It is apparent that stereotypes may play a role in when and to what extent a witness is believed because jurors may have specific beliefs about the abilities of child witnesses. These stereotypes may be related to both the age of the witness and the witness's demeanor while testifying. It is possible that the child's credibility may depend on the violation or validation of jurors' stereotypes regarding how children should behave at certain ages. It may be that these stereotypes cause jurors to pay more attention to the age of the child and how the child presents while testifying, rather than the actual veracity of the child's testimony. Thus, perceptions of the child's credibility may be based more on preconceived beliefs of the juror rather than on the determinative facts of the case.

\section{Children as Credible Witnesses}

As mentioned, the stereotypes jurors have about children heavily influence how honest, accurate, capable, and suggestible a child may be perceived. These stereotypes also may influence jurors' judgments about the child's credibility as a witness. Research on the credibility of child witnesses is contradictory. Because historically children have been viewed as immature, lacking in certain capacities and, ultimately, inferior to adults, children have been categorized as unreliable witnesses, unable to make informed decisions or provide credible information (Woolard, Reppucci, \& Redding, 1996). In comparison to adults, some studies have found that children are perceived as less credible than adults (e.g., Goodman, Golding, Helgeson, Haith, \& Michelli, 1987; Leippe, Manion, \& Romanczyk, 1993). For example, Goodman et al. (1987) studied whether mock-juror perceptions of credibility varied depending on whether testimony was given by 6-, 10-, or 30-year-old eyewitnesses in vehicular homicide or murder cases. They found that the credibility of an eyewitness increased with age, with the child eyewitnesses rated as less credible than adult eyewitness. 
However, other studies have found that children are perceived as at least as credible, if not more so, as adults (e.g., McCauley \& Parker, 2001; Ross, Miller, \& Moran, 1987; Nikonova \& Ogloff, 2005). Ross et al. (1987), for example, presented mock jurors with drug case transcripts in which the key witness was a child, a young adult, or an elderly witness. They found that witness age was negatively correlated with credibility, with testimony of a child rated as more accurate, confident, forceful, honest, and credible compared to both the young adult and the elderly witnesses. Ross et al. (1990) also studied mock-jurors' perceptions of witnesses varying age of the witness to be either 8-, 21-, or 74-years-old. They found that after viewing a child witness testifying, mock-jurors believed children to be more credible than both elderly and young adult witnesses. Thus, age can be used as an indicator of accuracy and credibility.

In addition to studying adult witnesses compared to child witnesses with regard to credibility, research has also examined how jurors' perceptions of credibility differ when comparing child witnesses of different ages. Research has indicated that when comparing older and younger children, the older a child witness is, the less his or her testimony is thought to be affected by suggestibility (Goodman \& Schaaf, 1997), the more trustworthy and competent he or she is perceived to be (Nikonova \& Ogloff, 2005), and the more mock jurors believe his or her testimony compared to a younger child (Newcombe \& Bansgrove, 2007). On the other hand, Gabora, Spanos, and Joab (1993) found that, in certain types of cases (e.g., sexual abuse cases), older children are less believed by mock-jurors, possibly because younger children are seen as more innocent and less likely to lie than older children. Research has also indicated that in these cases younger children may be viewed as more truthful, accurate, and believable than older children (Holcomb \& Jacquin, 2008; Schmidt \& Brigham, 1996). Wright, Hanoteau, Parkinson, and Tatham (2010) found that perceived reliability was not linear with age and reliability and 
honesty ratings dramatically increased for children until the age of 6-years-old, but, after that, variations occur and age does not play as significant a role.

Thus, the research is contradictory as to whether age plays a significant role in the determination of a child's believability and reliability when testifying. It is possible that the inconsistent research results concerning the credibility of child witnesses may be attributed to a number of different factors, one of which may be the type of case in which the child is involved. Past research has used a number of different types of cases when examining juror perceptions about a child's credibility as a witness. It is possible that jurors' perceptions of child witnesses' credibility vary based on the type of case in which the child is involved.

\section{The Importance of Type of Case}

Much of the research about juror perceptions of child witnesses has utilized case scenarios based upon sexual abuse, in which the child is the sole witness. These types of cases are chosen because of the fact that children, when called to testify, most often do so in sexual abuse cases. Research has found that in cases where children are testifying about sexual abuse, jurors tend to believe younger children more than older children and adults, because they are inexperienced and lack the relevant knowledge to create a believable story of sexual activities (Goodman et al., 1987). Thus, credibility of a child witness depends on his or her expertise and honesty. Further, in sexual abuse cases, child witnesses are often viewed as more credible than adult witnesses because adults believe children have less motivation to lie, with the witness's credibility resting on either the accuracy or honesty of the testimony (Ross et al., 1990). Thus, a child's limited cognitive abilities concerning sexual knowledge may actually enhance their credibility (Ross et al., 1990). According to Nightingale (1993), jurors find it difficult to believe that a child could have such specific sexual knowledge unless the event actually occurred. 
Research on the role of children in other types of cases like robbery, murder, vehicularhomicide, and medical-malpractice has been limited. However, it has been found that in these cases older children are viewed as more credible than younger children (Goodman, Golding, Hegelson, Haith, \& Michelli, 1987; Leippe \& Romanczyk, 1989). When comparing how child witnesses were viewed in sexual abuse cases versus robbery cases, McCauley and Parker (2000) found that child witnesses were viewed as more credible and honest in sexual abuse cases compared to robbery cases, regardless of the child's age. It may be that in sexual abuse cases children are viewed as more innocent, while in non-sexual abuse cases children are believed to have more motivation to lie. If this is the case, jurors' initial perceptions of the credibility of the child testifying may be related to the type of case being tried.

It is possible that in addition to impressions of credibility, the type of case may also impact other judgments about child witnesses of different ages, specifically, the amount of blame attributed to child witnesses of different ages by jurors and the extent to which he or she should be held accountable for his or her victimization. Nightingale (1993) examined how a victim's age may affect mock juror decisions in a sexual abuse case and identified a negative bias toward child victims approaching adolescence. It was found that the amount of blame attributed to the victim increased with age. More specifically, 6- and 9-year-olds were equally blamed for their victimization, while 12-year-olds were blamed the most by mock jurors. The results suggested that a young child was viewed as a true victim, with more mock jurors holding the older child accountable, expecting her to have better judgment (Nightingale, 1993). Further, Duggan et al. (1989) found an effect of age on mock juror verdicts and blame ratings in that 9-year-old witnesses were believed more and mock jurors gave more guilty verdicts than they did for the 5or 13-year-old scenarios. Duggan et al. (1989) explained that the reason for this finding may 
have been that 13 -year-olds were viewed with suspicion and blamed for their victimization, and 5-year-olds may have been viewed as more susceptible to the influence of external sources. Additionally, both Nightingale (1993) and Duggan, et al. (1989) found that the relationship between age and verdict decisions changed when there was corroborating evidence. Mock jurors were more likely to give a guilty verdict when the testimony of an older child was corroborated, because then less blame was attributed to the victim (Nightingale, 1993; Duggan et al., 1989). However, the younger the child, the more mock jurors were willing to believe the child's testimony without corroborating evidence (Nightingale, 1993). As the research shows, the relationship between the age of a child witness, and the degree of credibility and blame assigned to the witness is complex and needs further exploration. This is especially true for non-sexual abuse cases, which have received less attention in the literature.

Since research on perceptions of child witnesses in a non-sexual abuse case is limited, especially regarding children of different ages, it is important to examine the different factors that influence a child's perceived credibility and attributions of blame in these cases. One of these factors may be the child's demeanor while testifying. It is possible that a child's demeanor, specifically his or her expression of emotion, may differ depending on the type of case in which he or she is testifying and this, then, may influence jurors' perceptions of credibility and verdict decisions. Just as jurors' beliefs about a child's age and capabilities as a witness influence judgments of credibility, their beliefs about how the child should behave while testifying may also affect credibility judgments.

\section{The Role of Demeanor}

The belief that demeanor and presentation style are strong indicators of the reliability and accuracy of information being communicated is widely held, even by legal professionals 
(Feldman \& Chesley, 1984). Throughout the trial process, the nonverbal behavior and presentation styles of those testifying are being evaluated by the trier of fact and used as measures of credibility. It is generally accepted that the demeanor of a witness is critical to judging the person's credibility (Blumenthal, 1993). Not only will the content of a witness's testimony be assessed, but his or her demeanor, including facial expressions, voice intonations, and displays of emotion, will be assessed as well (Golding, Dunlap, \& Hodell, 2009). Generally, people expect certain displays of emotion in certain situations. These expectations are formed based on how a person believes he or she would respond when faced with the same situation.

People have the ability to take on the role of another, leading them to determine what the most appropriate reactions are for a given setting (Tsoudis \& Smith-Lovin, 1998). Tsoudis and Smith-Lovin (1998) examined how emotional displays by a victim while testifying affected mock-juror perceptions and verdict decisions. They found that when the victim displayed a relaxed or unconcerned emotional state, his or her credibility was evaluated negatively and the severity of the crime was minimized, resulting in a lower likelihood of guilty verdicts. The more apparent a victim's distress was, the more responsibility and blame was placed on the alleged perpetrator (Tsoudis \& Smith-Lovin, 1998). These findings may be explained in that jurors may believe negative events induce negative (sad or angry) emotions, causing them to look for the demonstration of these emotions when a victim is testifying. Thus, if a juror believes a victim of a crime should be distressed and that victim testifies in a calm manner, the juror is less likely to accept the victim as a credible source of information (Tsoudis \& Smith-Lovin, 1998). Therefore, expressions of emotion can significantly impact the perceived credibility of a witness, especially if they match juror expectations (see also Dahl et al., 2007; Kaufman, Drevland, Wessel, Overskeid, \& Magnussen, 2003, for similar findings). 
A victim-witness that presents with less emotion in response to a crime may be perceived as less credible and receive less sympathy, as noted, because people expect that the severity of the victim's emotional response should match the seriousness of the event in question (Rose, Nadler, \& Clark, 2006). Just as this expression of emotion influences perceived credibility of witnesses, it also impacts other perceptions about a witness. Ask and Landstrom (2010) found that a victim-witness was perceived as more truthful when they communicated in an emotional, compared to a neutral, manner. Bollingmo, Wessel, Eilertsen, and Magnussen (2007) also found that a victim was judged as more credible when they cried or showed despair compared to when they were neutral or expressed a positive emotion. It may be that the degree of emotionality expressed while testifying may affect the credibility of the witness in the eyes of jurors, as it may be used as an indication of honesty.

The type of emotional expression can also affect the amount of punishment imposed on the perpetrator. Nadler and Rose (2003) found that when a victim-witness presented with a mild emotional reaction, he or she was viewed with less sympathy and the perpetrator received a lesser sentence. Therefore, the research indicates that the expression of emotion plays an important role in the assessment of a witness's credibility and the sentencing of a defendant; however, most of this research is based on adult witnesses, specifically with regard to expressions of emotion. It may be that the expectations jurors have of children's capabilities as accurate witnesses differ from the expectations they have of adult witnesses. Research is limited on how a child's emotionality while testifying affects juror perceptions of credibility and verdict decisions and has not examined how expression of affect interacts with other factors like juror stereotypes of children, blame attribution and a child's age.

\section{A Child Witness's Expression of Affect}


Myers, Prizmich, Redlich, Goodman, and Imwinkelried (1999) examined actual juror perceptions of emotional children testifying in a sexual abuse case. They found that the degree to which the child's facial expressions, gestures, movements, eye contact, nervousness, and manner of speaking were perceived as important positively correlated with actual jurors' decisions of whether or not to believe the witness. The researchers noted that $16 \%$ of the jurors surveyed indicated that crying was the most influential emotion displayed by a child while testifying. Therefore, a child witness whose distress is evident while testifying may be more believed than a child witness who does not show how the alleged crime affected them.

The emphasis on emotional expression may be problematic given the fact that children do not always react to stressful events in the expected or same way as adults. Children have a lower tolerance for depressive moods than adults and often respond in inappropriate ways in an effort to recapture a pleasurable feeling (Duncan, 2002). By denying the reality of a bad situation, the child is able to create defenses against the situation and attempt to ignore the fact that something traumatic has happened (Duncan, 2002). Children who have been maltreated do not necessarily cry or display strong emotions when disclosing their experiences (Sayfan, Mitchell, Goodman, Eisen, \& Qin, 2008). Often, these children will present with a neutral expression of affect (Sayfan, Mitchell, Goodman, Eisen, \& Qin, 2008). Further compounding matters is the fact that child trauma victims can have language delays averaging 9 to 10 months behind 'normal' children (Hecht et al., 1986). Since children may not react to a negative event in the same way as an adult, a juror may discredit a child as a witness without carefully listening to the child's testimony.

There are a number of other factors affecting the level of emotion a child displays while in court. For example, before going to court, children are often instructed about court processes 
and what they should expect when testifying, all of which can limit their emotional displays (Talwar, Lee, Bala, \& Lindsay, 2006). Other factors that may influence a child's emotional display include preparation about court procedures, knowledge that the defendant will be present but unable to harm him or her, multiple interview sessions, and a delay between the time of the crime and the child's court appearance (Regan \& Baker, 1998). Attorneys agree that preparation about court proceedings can reduce a child's confusion, hesitation, and uncertainty, and can lead to children presenting as more confident and with a more emotionally controlled demeanor (Regan \& Baker, 1998). Thus, the degree to which a child is emotionally expressive may fluctuate, due to many different factors. When this happens, the child's perceived credibility may be damaged.

Therefore, as noted, if children do not present with expected emotional displays, jurors may deem them less credible. Regan and Baker (1998) examined how, in a sexual abuse case, a child witness's demeanor at the moment of courtroom confrontation with the defendant affected the trial outcome and the perceived credibility of the child victim-witness. The researchers found that mock jurors used a child victim-witness's demeanor at the moment of confrontation to guide their evaluations about the child's credibility. Children who cried when seeing the defendant, compared to those who remained calm, were viewed as more credible, honest, believable, accurate, and reliable (Regan \& Baker, 1998). On the other hand, when the child witness remained calm, contradicting mock juror expectations, the child was viewed as less credible (Regan \& Baker, 1998).

Golding et al. (2003) extended Regan and Baker's (1998) study, examining the effect of a child victim-witness's demeanor while testifying and expanded the variable to include hysterical crying in addition to calm and teary-eyed, on mock jurors' verdict decisions and assessment of 
the witness's credibility. Golding et al. (2003) also examined the age of the victim, presenting the child as either age 6 or 15. Participants read a brief written summary of a fictional trial about a man accused of first degree rape of his neighbor's daughter. The witness's behavior, whether she cried hysterically, became teary, or remained calm, was mentioned once in the narrative as she was testifying. The researchers also used courtroom drawings to illustrate the demeanor of the witness. They found that mock jurors who saw witnesses become teary gave more guilty verdicts and found the witness more believable. It appeared that tearing up, compared to crying hysterically or remaining calm, was the optimal level of crying that mock jurors expected a child victim to exhibit while testifying (Golding et al., 2003). However, the researchers did not find an age effect for how mock jurors viewed 6 and 15-year-old witnesses. Therefore, it is evident that a child's expression of emotion while testifying also may impact jurors' perceptions of credibility. Research has shown that age differences do affect jurors' credibility judgments and blame attributions. Though it has never been studied, it is possible that a child's expression of affect may also influence differences in blame attribution. The role of a child's emotionality in the determination of credibility and blame attribution has not been examined in a non-sexual abuse case. It is possible that the effect of a child's emotionality on witness credibility will vary when the type of case is different.

\section{The Current Study}

The courts have recognized how a child's testimony can provide an important piece of evidence, and have allowed children to testify in court when necessary, but it is up to jurors to decide if the child's testimony is credible. Jurors often have stereotypes about children's cognitive abilities, accuracy, and maturity, which they apply when judging the credibility of a child's testimony. Jurors may also believe that certain expressions of affect indicate truthfulness. 
If a child witness presents with behaviors that contradict how jurors believe they should behave, or that jurors believe to indicate deception, the child's testimony may not be deemed credible.

Previous research has found that children who cried upon first seeing the defendant in court were rated as more credible by jurors, resulting in more guilty verdicts than when jurors viewed children who remained calm (Regan \& Baker, 1998). Studies have also shown that a child's demeanor while testifying affected jurors' decisions and beliefs about the child's credibility as a witness such that children who became teary, compared to those who remained calm or cried hysterically, were viewed as the most credible, resulting in the most guilty verdicts (Golding et al., 2003). While Golding et al. (2003) did not find an effect for child witness age, Duggan (1989) did find a significant age effect, with the number of guilty verdicts and the witness's perceived credibility decreasing, and the amount of blame attributed to the child increasing, as the age of the child witness increased. Nightingale (1993) also found that an older child witness was blamed for her victimization more than a younger child witness. Therefore, it is important to examine whether the age of a child witness, combined with the demeanor of the child while testifying, affects jurors' perceptions of witness credibility, case verdict decisions, and the amount of blame jurors attribute to the witness.

The purpose of this study is to investigate the effect of a child witness's age and expression of affect, specifically crying while testifying, on mock jurors' assessment of the witness's testimony credibility, blame attributed to the child witness, and verdict decision. Consistent with Duggan (1989), it is hypothesized that a 6-year-old child will be viewed as more credible than a 13-year-old. It is also hypothesized that children who cry while testifying will be viewed as more credible than those who remain calm, consistent with Regan and Baker (1998) and Golding et al. (2003). Consistent with Nightingale (1993), it is hypothesized that a 6-year- 
old witness will be blamed less than a 13-year-old witness, and that a witness who cries while testifying will be blamed less than a witness who remains calm while testifying. Finally, it is also hypothesized that 6-year-old children who cry will be viewed as the most credible witnesses and with jurors giving the most guilty verdicts in this scenario.

\section{Method}

\section{Participants}

The sample consisted of 186 undergraduate students from Roger Williams University. All participants were at least 18 years of age and, therefore, were at least jury eligible. They received course credit in return for their participation in the study.

\section{Materials and Procedure}

Informed consent (Appendix A) was obtained from each participant before the experiment began. A simulated trial with a female victim aged 6 or 13, who was exhibiting a specific demeanor (calm or crying) while testifying, was used; resulting in four different transcripts (see Appendix B). A victim-witness was used over an eye-witness as it would be more realistic that a victim would get emotional while testifying. Also, a 6-year-old was chosen, as it was believed to be the youngest age a child would be allowed to walk home from school. The trial transcripts used in this study were based on transcripts developed by McCauley and Parker (2001). McCauley and Parker's transcripts reflected in-court dialogue between attorneys and the witness in a trial describing the aggravated robbery of a female child by an adult male. The scenarios were modified so that features that would have increased believability (e.g. the addition of valuable items in the girl's backpack) were enhanced and those that did not were dropped (e.g. the lost dog of the perpetrator). In addition, the location of the alleged incident was changed from Wyoming to Connecticut in order for the trial to be more personally relevant 
to the participants as they were on the East coast. Evidence in the trials was held constant across conditions and no physical evidence was presented in the transcripts. The scenarios were set up so that the jurors' belief in the child's testimony would be the critical factor in determining the verdict. In all cases presented, the victim testified that she walked through a park, which she had been told to avoid, when a man grabbed her, pulled her behind the bushes, and then assaulted her and took her belongings. The victim's narrative was slightly altered to reflect the specific demeanor she was exhibiting while testifying and her age and grade in school. The format of the trial transcripts was as similar to actual court transcripts as possible in order to increase realism. Participants were assigned randomly to read one of the four trials and were asked to take the case seriously, as if they were actual jurors. They were notified that they would be asked questions about the scenario later. A cover sheet was included to inform participants that they were reading an excerpt from a trial that took place on May 30, 2009 in Connecticut.

After reading the transcript, participants were asked to fill out a questionnaire (Appendix C) assessing the credibility of the witness, guilt of the defendant and amount of blame attributed to the witness. Scores for overall credibility were calculated by summing the scores from each question related to the credibility and believability of the witness's testimony and the jurors' perceptions of the witness. Possible scores on this measure ranged from 0 to 35 . Blame attribution was measured by asking participants to assign a percentage of blame to the victim from 0 to 100 and then provide a written response as to why they blamed her. Participants' verdict decisions were multiplied by their certainty ratings for a possible range of scores from -5 to 5, resulting in a confidence in verdict score. A score of 5 indicated that participants were as certain as possible in their verdict decision of guilty, while a score of -5 indicated the least amount of certainty possible in verdict decision of not guilty. Finally, two manipulation checks 
were included. The first asked participants to describe the behavior of the victim-witness as she was testifying. The second manipulation check asked participants to rate how calm the witness was while testifying on a 5-point Likert scale ranging from not at all calm to very calm. After completing the questionnaire, participants were read a debriefing statement (Appendix D) and were given credit for their participation.

\section{Results}

This experiment was a 2 (age of child witness) X 2 (behavior of child while testifying) between-subjects factorial design. The participants were randomly assigned to conditions. The alleged victim displayed either a calm or crying behavior while testifying and was presented as either 6-or 13-years old. This study aimed to investigate impact of age and behavior while testifying on verdict, witness credibility, and attribution of blame.

\section{Preliminary Issues: Manipulation Check}

Of the 186 participants surveyed for this study, 64 were discarded due to a failure of the manipulation check (i.e. failure to recognize that the child was crying while testifying). For the first manipulation check, participants were asked to provide a written description of the witness's behavior while testifying. In this study, it was imperative that participants recognized the child's crying behavior while testifying, therefore, for the crying scenarios, any written response other than "crying" resulted in the participants' data being discarded. However, even for the participants whose data were retained, $30 \%$ described the witness as "confident", "sure of herself”, and/or “certain", regardless of age or expression of affect, revealing potential issues with the main manipulation in this study. Also, $72.5 \%$ of the participants who were retained noted other behavior characteristics in addition to the crying behavior like being "nervous", "scared", and "shy". 
Continued evidence for these issues was found in the second manipulation check that asked participants to rate how calm the witness was while testifying. The results indicated that in the 6-year-old crying condition, $43.3 \%$ of participants indicated that the witness was either "somewhat calm" or "calm" while testifying. This trend was also apparent in the 13-year-old crying condition in which $40.7 \%$ of participants indicated the witness was either "somewhat calm" or "calm" while testifying. As a whole, $68.8 \%$ of participants found that the witness was "somewhat calm", "calm", or "very calm" while testifying even though $50 \%$ of the cases presented were of a witness crying. The percentages presented suggest that the case scenario failed to adequately distinguish between a "calm" witness and a "crying" witness resulting in limited variability.

\section{Determinations of Guilt}

Regardless of the age of the witness or whether the witness was calm or crying while testifying, $77.9 \%$ of participants chose guilty verdicts. A Chi-square test for independence indicated no significant differences in the distribution of verdict decisions among case scenarios, $\aleph^{2}(122)=3.61, p>.05$, in that participant verdict decisions did not differ based on which scenario (and, therefore, which combination of child age and expression of affect) they read.

Additionally, a two-way between-groups analysis of variance was conducted to explore the impact of age and expression of affect while testifying on confidence in verdict decision. The interaction effect between age and expression of affect reached marginal statistical significance, $F(1,118)=3.04, p=.08$ (See Figure 1 for a graph of the interaction between age and expression of affect). A trend was noticed in which participants reading about 6-year-olds who cried $(M=2.70, S D=2.72)$ were more confident in their verdict decisions than those who read about 6-year-olds that remained calm $(M=1.83, S D=3.39)$ and participants who read 
about 13-year-olds who cried $(M=1.78, S D=3.15)$ were more confident in their verdict decisions than those who read about 13-year-olds that remained calm $(M=2.80, S D=2.59)$. While this trend did not reach statistical significance, the means were in the expected direction. The main effect for age, $F(1,118)=.002, p>.05$, did not reach statistical significance, meaning that participants were no more confident in their verdict decisions when reading about a 6-yearold child $(M=2.27, S D=3.08)$ than when reading about a 13 -year-old child $(M=2.27, S D=$ 2.92). The main effect of expression of affect, $F(1,118)=.02, p>.05$, also did not reach statistical significance, which means that participants were no more confident in their verdict decisions when reading about a child who cried while testifying $(M=2.23, S D=2.96)$ than when reading about a child who remained calm $(M=2.32, S D=3.03)$ while testifying.

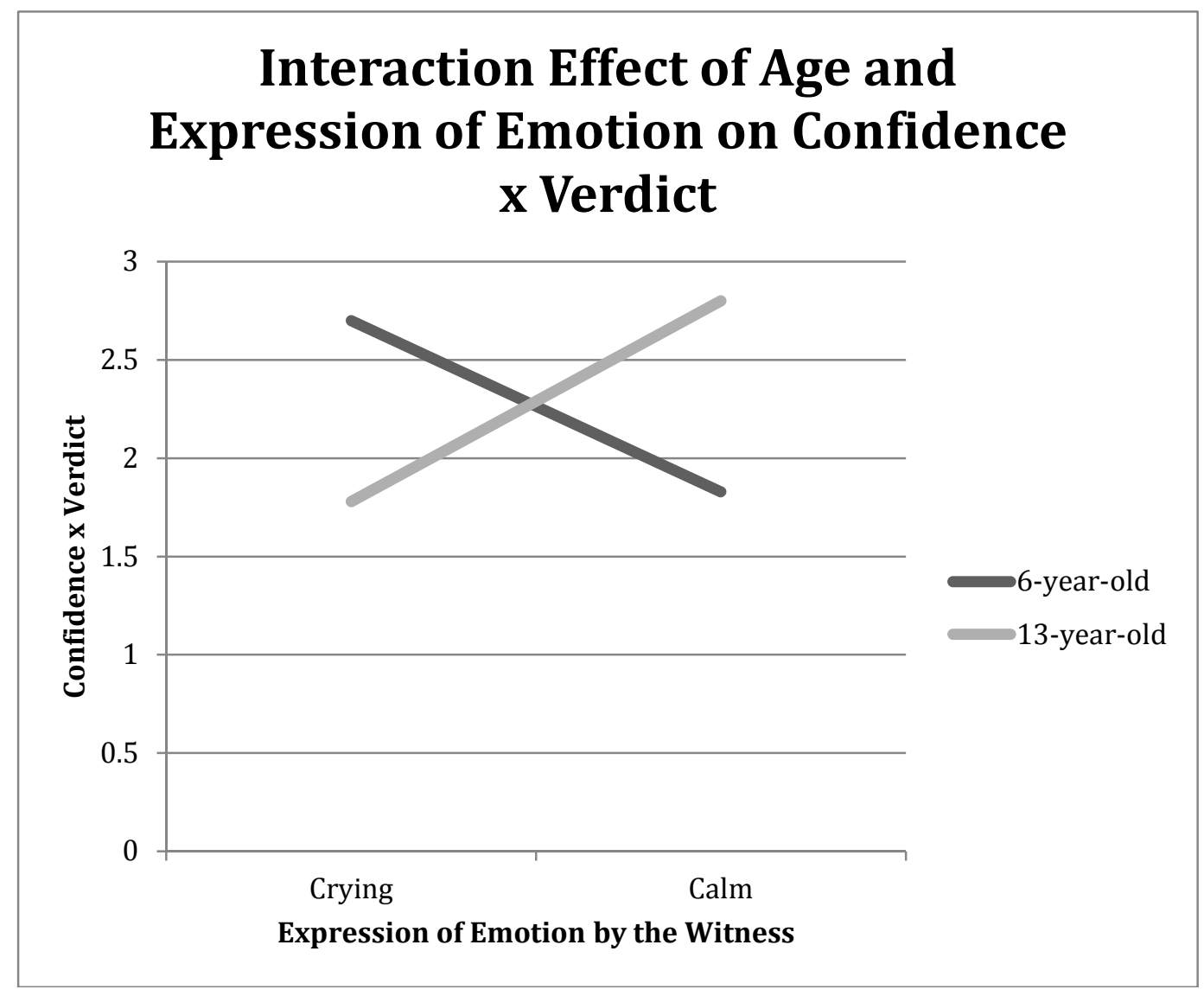

Figure 1: Interaction effect of child witness age and expression of emotion while testifying on participants' confidence in verdict decisions. $F(1,118)=3.04, p=.08$. 


\section{Credibility of the Victim-Witness}

A two-way between-groups analysis of variance was conducted to explore the impact of age and expression of affect while testifying on credibility scores, as measured by the Overall Credibility Score. Reliability analyses were conducted on the eight items for the Overall Credibility Scale. The Overall Credibility Scale had good internal consistency, with a Cronbach alpha coefficient reported of .81. Therefore, the Overall Credibility Scale items were combined into a single variable called the Overall Credibility Score. The interaction effect between age and expression of affect did not reach statistical significance, $F(1,118)=1.30, p>.05$, which means that participants did not view a crying 6-year-old $(M=27.93, S D=4.00)$ as more credible than a crying 13 -year-old $(M=26.19, S D=4.18)$, nor did they find a calm 6 -year-old $(M=$ 27.43, $S D=4.14)$ more credible than a calm 13 -year old $(M=27.30, S D=3.19)$ (See Figure 2 for a graph of the interaction between age and expression of affect). Though the interaction did not reach statistical significance, the means did yield a trend in the expected direction, in which crying 6-year-olds were viewed to be more credible than crying 13-year-olds, and calm 6-yearolds were judged to be more credible than calm 13 -year-olds.. The main effect for age, $F(1,118)$ $=1.77, p>.05$, also did not reach statistical significance which means that participants did not find a 6 -year-old witness $(M=27.68, S D=4.04)$ any more credible than a 13 -year-old witness $(M=26.73, S D=3.74)$. Finally, the main effect of expression of affect, $F(1,118)=.19, p>.05$, also did not reach statistical significance, meaning that participants rated child witnesses as equally credible, regardless of whether the child remained calm $(M=27.37, S D=3.66)$ or cried $(M=27.03, S D=4.15)$ while testifying. 


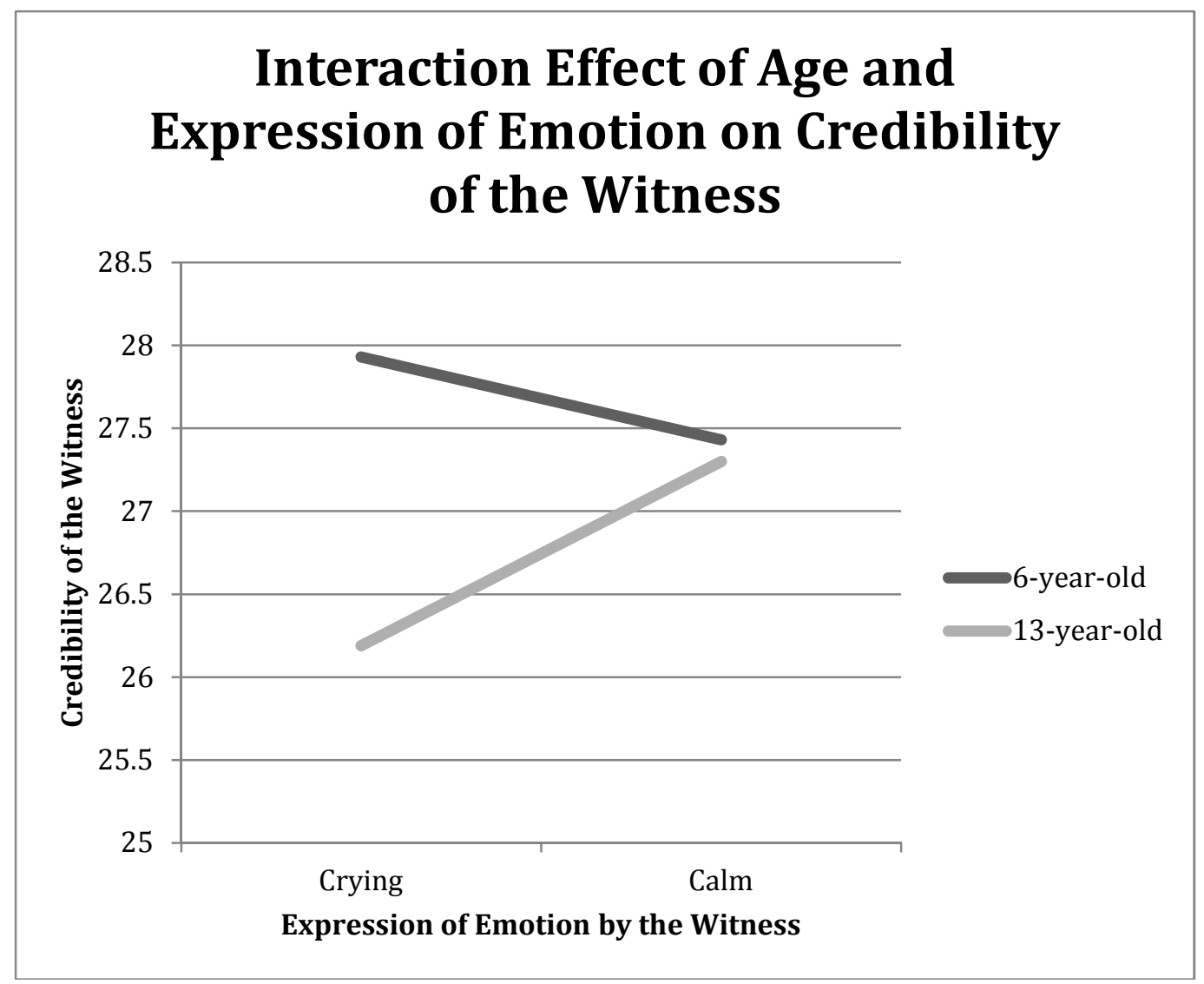

Figure 2: Interaction effect of child witness age and expression of emotion while testifying on participants' perceptions of witness credibility. $F(1,118)=1.30, p>.05$.

\section{Attribution of Blame}

A two-way between-groups analysis of variance was conducted to explore the impact of age and expression of affect while testifying on amount of blame placed on the witness. The interaction effect between age and expression of affect was not statistically significant, $F(1,118)$ $=.48, p>.05$, meaning that participants did not blame a crying 6-year-old $(M=12.00, S D=$ 13.87) any less than a crying 13 -year-old $(M=12.97, S D=20.84)$, nor did they blame a calm 6year-old $(M=14.50, S D=23.39)$ any less than a calm 13 -year-old $(M=10.80, S D=14.11)($ See Figure 3 for a graph of the interaction between age and expression of affect). Though the interaction was insignificant, the means did yield a trend in the expected direction, with crying 6- 
year-olds being blamed less than crying 13-year-olds and calm 6-year-olds being blamed less than calm 13-year-olds. The main effect for age, $F(1,118)=.17, p>.05$, did not reach statistical significance which means that participants did not attribute any less blame to 6-year-olds $(M=$ $13.25, S D=19.10)$ than they did to 13 -year-olds $(M=11.9, S D=17.79)$. The main effect of expression of affect, $F(1,118)=.002, p>.05$, did not reach statistical significance, meaning that participants did not blame calm witnesses $(M=12.65, S D=19.24)$ any more than witnesses who cried $(M=12.50, S D=17.67)$ while testifying.

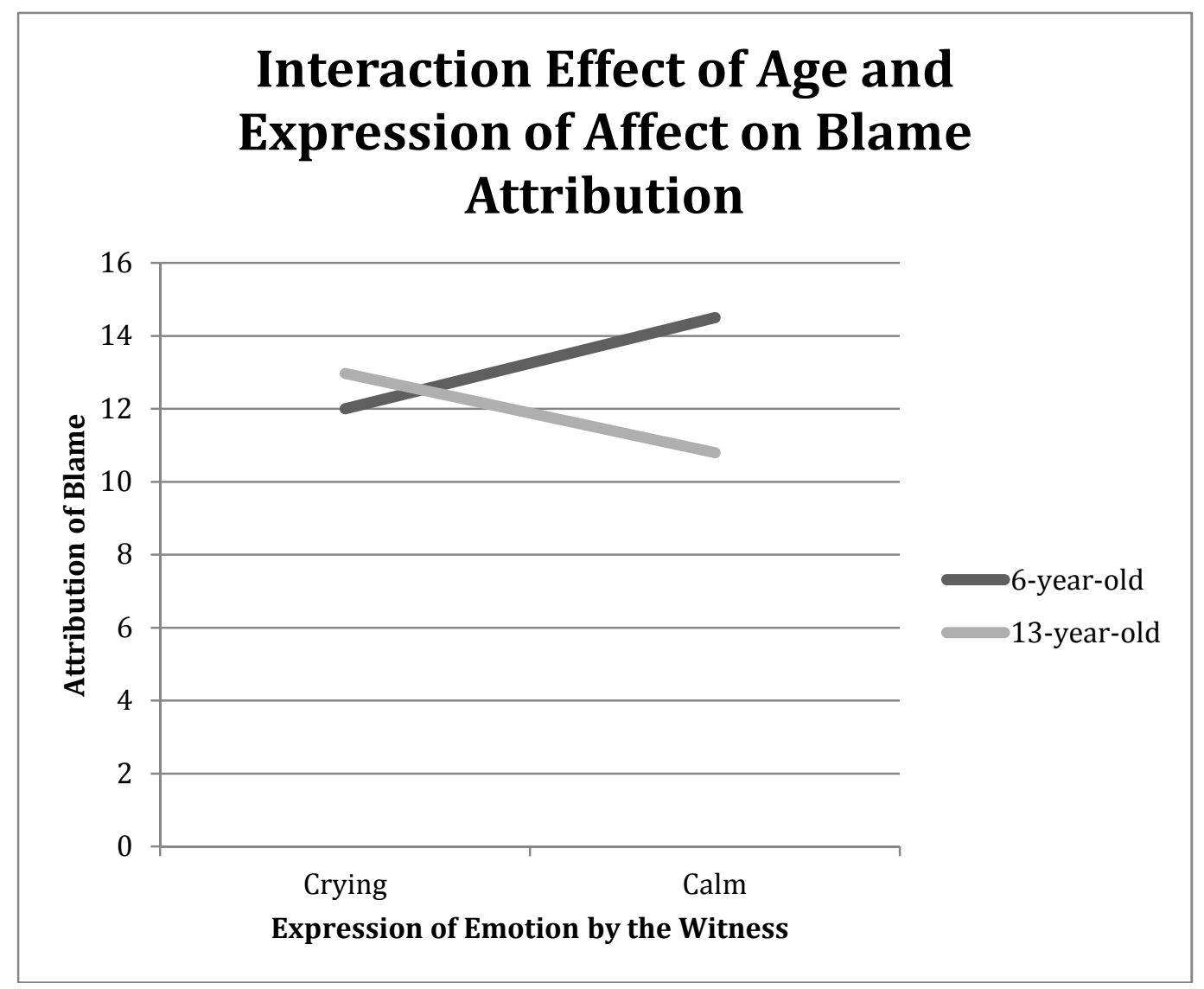

Figure 3: Interaction effect of child witness age and expression of affect while testifying on amount of blame attributed to the witness. $F(1,118)=.48, p>.05$.

Though interactions with blame were not significant, $68.1 \%$ of participants attributed at least some percentage of blame to the witness for her victimization. Almost half (49\%) of the 
participants who attributed some amount of blame to the child did so because she "knew better than to walk through the park", as was most commonly noted in the free response section that inquired why the participant gave the blame rating to the witness. The amount of blame assigned to the child for her victimization by participants ranged from $1 \%$ to $100 \%$, with the average allotted amount of blame being $12.57 \%$. Six-year-olds, regardless if the child was crying or remained calm, were blamed only $55 \%$ of the time (Range $=5-100 \%, \mathrm{M}=24.1 \%$ ) while 13 year-olds were blamed $61.3 \%$ of the time (Range $=1-85 \%, \mathrm{M}=19 \%)$. While this trend was in the expected direction, it was not significant.

\section{Discussion}

This study examined the effect of a child victim-witness's age and expression of affect while testifying on mock-jurors' perceptions of the child's credibility and amount of blame attributed to the child for her victimization. It was expected that children who cried would be viewed as more credible, consistent with Golding et al. (2003) and Regan \& Baker (1998) and that older children would be blamed more for their victimization than younger children consistent with Nightingale (1993) and Duggan et al. (1989). It was also expected that the younger child who cried while testifying would be perceived as the most credible witness and that these cases would result in the most guilty verdicts. Unfortunately, these hypotheses were not supported.

Contrary to expectations, the victim-witness's age had no impact on jurors' perceptions of the witness's credibility, verdict preference or blame attribution. The lack of effect of age on credibility perceptions and verdict decisions is consistent with Wright et al. (2010) who did not find a difference in reliability ratings for children after age six. The findings are also consistent with Nightingale (1993) who only found a tendency of jurors rating older victims as less 
believable after she had expanded the age variable from 6, 9, and 12-years-old to ages 6 through 14. Thus, it appears that age may not play as significant a role in credibility judgments of child witnesses for non-sexual abuse cases (except perhaps as found by Wright et al., for children below age six). It may be that in these types of cases there is no standard to base credibility judgments upon, unlike sexual abuses cases where younger children are viewed as innocent and are supposed to be without specialized knowledge of sexual acts. Therefore, jurors' stereotypes about child witnesses in non-sexual abuse cases may be based more on beliefs about children in general, rather than on comparisons of older versus younger children. The results of the current study would lend support for such an explanation.

However, the lack of findings concerning witness age is inconsistent with studies that found the age of a child influences jurors' credibility judgments. Though contradictory, some studies have found that older children were perceived as more trustworthy and competent than younger children (Nikonova \& Ogloff, 2005; Newcombe \& Bansgrove, 2007), while other studies found that younger children were viewed as more innocent, truthful, accurate and believable than older children (Gabora, Spanos \& Joab, 1993; Holcomb \& Jacquin, 2008; Schmidt \& Brigham, 1996). Of note is the fact that these studies found an effect for age when utilizing audio or video stimulus materials. Therefore, it is possible that no effect of age was found because the current study used a written transcript. It may be that only after seeing children of different ages that the age of the witness becomes salient and thus becomes a factor in jurors' credibility judgments. Therefore, in order to be more confident in the findings that age does not play as significant a role in non-sexual abuse cases, it would be important to replicate this study using an audio or visual format similar to those used in pervious studies, while holding all other variables constant. 
The expression of affect also failed to impact mock-juror perceptions of credibility, verdict decisions and blame attributions. However, a trend was noticed in which jurors' confidence in verdict decision increased when a 6-year-old child cried, compared to when the 6year-old remained calm. The same was true for when a 13-year-old child cried. It is possible that with more participants this trend may have reached statistical significance. If this trend were to become significant, it would support the findings of Golding et al. (2003) and Regan and Baker (1998), both of which found that child victim-witnesses were viewed as more credible when they cried compared to when they remained calm. It is of note that past research utilized only sexual abuse cases. It may be that the expression of affect plays the same role in credibility judgments in non-sexual abuse cases as it does in sexual abuse cases.

The lack of effect for expression of affect may also be due to the presentation of the crying behavior in the transcript. In an attempt to keep the transcript as realistic and as similar to real court trial transcripts as possible, the child's emotional displays were only noted by inserting the word "crying" four times throughout the transcript. It is possible that if a participant was not paying close attention they may have missed the notation. It may be that participants interpreted the limited notation of crying behavior as a fluctuation in the child's expression of emotion. This fluctuation may have been viewed as an inconsistent behavior pattern, which may have limited the impact of the crying behavior on perceptions of credibility. Some participants also noted other behavior characteristics, such as nervousness and confidence, along with crying. It is possible that participants placed more emphasis on those other behaviors and, therefore, the impact of the crying behavior was minimized. The second manipulation check revealed that more than half of participants indicated the child witness was calm to some degree while testifying, even though half of the scenarios were of a child crying. The indication of calmness 
regardless of whether the child was crying or not, may be an indication that participants did not fully focus on the crying notations in the transcript. It is also possible that the calmness perceived by jurors may have contradicted their expectations of how the child should have behaved while testifying, thus limiting the impact of the included crying behavior on perceptions of credibility. Finally, it is also possible that previous research found an effect for expression of affect because the crying behavior was presented in a more descriptive way. Golding et al. (2003) used a visual cue and presented drawings of the child either crying or remaining calm while testifying and Regan and Baker (1998) included of a vivid description of the crying behavior in the narrative. It is very possible that the scenarios used in this study did not depict the crying behavior well enough to cause jurors to emphasize it in their judgments of witness credibility. Again, it is possible that the behavior must be seen in order to have the full impact on jurors, as reading about crying and seeing a child crying would likely result in very different reactions.

The transcript may also have presented the child in a way that violated juror perceptions of how children should present themselves while testifying. When asked to describe the behavior of the witness, one-third of the participants indicated that they found the child to be confident while testifying, regardless of age or expression of affect. It may be that participants' stereotypes about children were disconfirmed for those who interpreted the witness as a "confident" child. The violation of participants' stereotypes would then be consistent with past research that found children who presented in a confident, mature manner violated juror stereotypes of child witnesses and were judged to be more credible than those who were viewed as childish (Leippe \& Romanczyk, 1989; Ross et al., 1990). It is important that future research continue to take into account the possible influence of juror stereotypes on perceptions of child 
witness credibility by including items addressing jurors' specific beliefs about children's capabilities as witnesses.

Though both Nightingale (1993) and Duggan et al. (1989) found that older child victimwitnesses were blamed more for their victimization than younger child victim-witnesses, this study did not confirm those findings and found that blame was not affected by either the witness's age or expression of affect while testifying. However, it is of note that a majority of participants did assign some degree of blame to the child for their victimization, with almost half attributing some amount of blame to the child because of her decision to walk through a park after being told not to. Regardless of whether a child was calm or cried while testifying, a slight trend of 6-year-olds being blamed less often than 13-year-olds was evident. Though this result was not statistically significant, it was in line with previous research.

Additionally, the trial transcript resulted in more guilty verdicts than not guilty verdicts. Most of the participants chose guilty verdicts, regardless of witness age or expression of affect. It may be that the robbery transcript (adapted from McCauley \& Parker, 2001) resulted in fewer guilty verdicts (and thus was less guilt prone) when used in comparison to a sexual abuse transcript. Without the comparison to a sexual abuse scenario, participants may have focused solely on the fact that the scenario depicted an attack on a child. It may be that any form of an attack on a child, whether sexual or not, has a higher likelihood of inducing a guilty verdict. Therefore, future replication of this study should utilize a more neutral transcript that depicts a different type of case, like breaking and entering or nonaggravated robbery, in order to effectively examine how the child's age and the expression of affect while testifying affect guilty verdict decisions. 
A clear issue in the current study was the transcript. As previously mentioned, it may not have provided a clear enough description of the crying behavior and was especially likely to elicit a guilty verdict regardless of the manipulation, thus, preventing any conclusions to be reached concerning the effects of age and expression of affect while testifying. It is possible that a more visible or descriptive representation of the child's crying behavior may result in a better manipulation of the independent variables. Therefore, if this study is to be replicated in the future, a different set of stimulus materials should be utilized, such as a video of the testimony. It is also important that a future replication of this study utilizes a more neutral, less guilt prone, scenario. Since most research involving child witnesses has centered on sexual abuse cases, it is important to continue to study how the nature of a case impacts a juror's perception of child witnesses, especially for cases not involving sexual abuse. 


\section{References}

Ask, K. \& Landstrom, S. (2010). Why emotions matter: Expectancy violation and affective response mediate the emotional victim effect. Law and Human Behavior, 34, 392-401.

Blumenthal, J. A. (1993). A wipe of the hands, a lick of the lips: The validity of demeanor evidence in assessing witness credibility. Nebraska Law Review, 72, 1157-1204.

Bollingmo, G. C., Wessel, E. O., Eilertsen, D. E., \& Magnussen, S. (2008). Credibility of the emotional witness: A study of ratings by police investigators. Psychology, Crime \& Law, 14, 29-40.

Dahl, J., Enemo, I., Drevland, G. C. B., Wessel, E., Eilertsen, D. E., \& Magnussen, S. (2007). Displayed emotions and witness credibility: A comparison of judgments by individuals and mock juries. Applied Cognitive Psychology, 21, 1145-1155.

Duggan III, L. M., Aubrey, M., Doherty, E., Isquith, P., Levine, M., \& Scheiner, J. (1989). The credibility of children as witnesses in a simulated child sex abuse trial. In S. J. Ceci, D. F. Ross, \& M. P. Toglia (Eds), Perspectives on the child witness (pp. 71-99). New York: Springer-Verlag.

Duncan, M. G. (2002). "So young and so untender": Remorseless children and the expectations of the law. Columbia Law Review, 102, 1469-1526.

Feldman, R. S. \& Chesley, R. B. (1984). Who is lying, who is not: An attributional analysis of the effects of nonverbal behavior on judgments of defendant believability. Behavioral Sciences \& The Law, 2, 451-461.

Gabora, N. J., Spanos, N. P., \& Joab, A. (1993). The effects of complainant age and expert psychological testimony in a simulated child sexual abuse trial. Law and Human Behavior, 17, 103-119. 
Golding, J. M., Dunlap, E. E., \& Hodell, E. C. (2009). Jurors’ perceptions of children’s eyewitness testimony. In B. L. Bottoms, C. J. Najdowski, \& G. S. Goodman (Eds.), Children as Victims, Witnesses, and Offenders: Psychological Science and the Law, (pp. 188-208). New York: The Guilford Press.

Golding, J. M., Fryman, H. M., Marsil, D. F., \& Yozwaik, J. A. (2003). Big girls don't cry: The effect of child witness demeanor on juror decisions in a child sexual abuse trial. Child Abuse \& Neglect, 27, 1311-1321. doi: 10.1016/j.chiabu.2003.03.001

Goodman, G. S., Golding, J. M., Helgeson, V. S., Haith, M. M., \& Michelli, J. (1987). When a child takes the stand: Jurors' perceptions of children's eyewitness testimony. Law and Human Behavior, 11, 27-40.

Goodman, G. S. \& Schaaf, J. M. (1997). Over a decade of research on children's eyewitness testimony: What have we learned? Where do we go from here? Applied Cognitive Psychology, 11, 5-20.

Hecht, M., Foster, S. H., Dunn, D. J., Williams, J. K., Anderson, D. R., \& Pulbratek, D. (1986). Nonverbal behavior of young abused and neglected children. Communication Education, 35, 134-142.

Holcomb, M. J. \& Jacquin, K. M. (2007). Juror perceptions of child eyewitness testimony in a sexual abuse trial. Journal of Child Sexual Abuse, 16, 79-95.

Kaufman, G., Drevland, G. B, Wessel, E., Overskeid, G., \& Magnussen, S. (2003). The importance of being earnest: Displayed emotions and witness credibility. Applied Cognitive Psychology, 17, 21-34.

Leippe, M. R. \& Romanczyk, A. (1989). Reactions to child (versus adult) eyewitnesses: The 
influence of jurors' preconceptions and witness behavior. Law and Human Behavior, 13, 103-132.

Leippe, M. R., Manion, A. P., \& Romanczyk, A. (1992). Eyewitness persuasion: How and how well do fact finders judge the accuracy of adults' and children's memory reports? Journal of Personality and Social Psychology, 63, 181-197.

McCauley, M. R. \& Parker, J. F. (2001). When will a child be believed? The impact of the victim's age and juror's gender on children's credibility and verdict in a sexual-abuse case. Child Abuse \& Neglect, 25, 523-539.

Melton, G. B. (1981). Children's competency to testify. Law and Human Behavior, 3, 73-85.

Myers, J. E. B., Prizmich, L. P., Redlich, A. D., Goodman, G. S., \& Imwinkelried, E. (1999). Jurors' perceptions of hearsay in child sexual abuse cases. Psychology, Public Policy, and Law, 5, 388-419.

Nadler, J. \& Rose, M. R. (2002). Victim impact testimony and the psychology of punishment. Cornell Law Review, 88, 419-453.

Newcombe, P. A. \& Bransgrove, J. (2007). Perceptions of witness credibility: Variations across age. Journal of Applied Developmental Psychology, 28, 318-331.

Nikonova, O. \& Ogloff, J. R. P. (2005). Mock jurors' perceptions of child witnesses: The impact of judicial warning. Canadian Journal of Behavioral Science, 37, 1-19.

Nightingale, N. N. (1993). Juror reactions to child victim witnesses: Factors affecting trial outcome. Law and Human Behavior, 17, 679-694.

Pennsylvania v. Ritchie, 480 U.S. 39 (1987).

Regan, P. \& Baker, S. (1998). The impact of child witness demeanor on perceived 
credibility and trial outcome in sexual abuse cases. Journal of Family Violence, 13, 187195.

Rose, M. R., Nadler, J., \& Clark, J. (2006). Appropriately upset? Emotion norms and perceptions of crime victims. Law and Human Behavior, 30, 203-219

Ross, D. R., Dunning, D., Toglia, M. P., \& Ceci, S. J. (1990). The child in the eyes of the jury: Assessing mock jurors' perceptions of the child witness. Law and Human Behavior, 14, $5-23$.

Ross, D. R., Miller, B. S., \& Moran, P. B. (1987). The child in the eyes of the jury: Assessing mock jurors' perceptions of the child wintess. In S. J. Ceci, M. P. Toglia, \& D. F. Ross (Eds.), Children's eyewitness memory (pp. 142-154). New York: Springer-Verlag.

Sayfan, L., Mitchell, E. B., Goodman, G. S>, Eisen, M. L., \& Qin, J. (2008). Children's expressed emotions when disclosing maltreatment. Child Abuse \& Neglect, 32, 10261036.

Schmidt, C. W. \& Brigham, J. C. (1996). Jurors' perceptions of child victim-witnesses in a simulated sexual abuse trial. Law and Human Behavior, 20, 581-606.

Talwar, V., Lee, K., Bala, N., \& Lindsay, R. C. L. (2006). Adults' judgments of children's coached reports. Law and Human Behavior, 30, 561-570.

Tsoudis, O. \& Smith-Lovin, L. (1998). How bad was it? The effects of victim and perpetrator emotion on responses to criminal court vignettes. Social Forces, 77, 695-722.

Woolard, J. L., Reppucci, D., \& Redding, R. E. (1996). Theoretical and methodological issues in studying children's capacities in legal contexts. Law and Human Behavior, 20, 219228.

Wright, D. B., Hanoteau, F., Parkinson, C., \& Tatham, A. (2010). Perceptions about memory 
reliability and honesty for children of 3 to 18 years old. Legal and Crimonological Psychology, 15, 195-207. 


\section{Appendix A}

Principal Investigator: Carly Hanks

1. Purpose of the Study: The purpose of this study is to examine jurors' perceptions of child witness testimony.

2. Procedures Experienced by Participants: If you agree to participate, you will read a trial transcript and be asked to answer questions about the trial. The total duration of your participation will be about 30 minutes.

3. Confidentiality and Anonymity: Only the investigator listed above and Dr. Cottle will have access to the identifiable records and data collected for this study, which will ensure your anonymity. Additionally, your name will only be written on this consent form, which will be collected and kept separate from your questionnaire. Thus, your responses will remain confidential.

4. Your Rights: Participation is voluntary and there is no penalty if you refuse to participate. If, at any point during the study, you feel uncomfortable or no longer want to participate, you may withdraw from the study without prejudice or penalty. Questions may be asked at any time during the study. Questions may be directed to the investigator (whose name and email address appear at the bottom of this form) at any time after participation in the study.

5. Compensation for Participation: Participants will be given class credit for their participation in this study.

6. Risks and Benefits of being a Participant: It is believed that the participants should experience no risks or discomforts. A potential benefit is that, based upon the response of the questionnaires, the participants may come to have a better understanding of psychological research. Consistent with the guidelines with the American Psychological Association, data will be stored in the office of the faculty member at least 5 years after the date of potential publication.

More Information: After participation, please feel free to contact Carly Hanks at chanks309@g.rwu.edu should you have any additional questions.

This certifies that I have given my full consent to participate in this study. I am at least 18 years of age or older. I have read this form and fully understand the content.

Participant's Signature

Date

This certifies that I have defined and informed the participant named above of all elements pertaining to this research study.

Principal Investigator

Date 


\section{Appendix B}

Child presented at age 6 or 13 and will be either Calm or Crying

IN THE ALBANY COUNTY SUPERIOR COURT

FOR THE STATE OF CONNECTICUT

The State of Connecticut )

$\mathrm{V}$.

Richard Martins

Defendant
PARTIAL TRANSCRIPTS OF

TRIAL PROCEEDINGS

This is a criminal trial for the aggravated robbery of Mary Anderson, against the defendant, Richard Martins. On May 30, 2009 at approximately 3:30 p.m. Mary Anderson, age [thirteen/six] was allegedly assaulted and robbed of her backpack as she was walking in Oak Hill park. The State will call two witnesses for the prosecution: Mary Anderson and Paul Young, a police officer.

The Defendant, Richard Martins, age thirty-six, claims that he was not the assailant and has pled not guilty to the charge of aggravated robbery .

Aggravated robbery is punishable in the state of Connecticut by not less than one year and not more then twenty-five years imprisonment.

Written below is an excerpt of the trial proceedings.

THE STATE'S CASE

\section{DIRECT EXAMINATION WITH MARY ANDERSON [THE VICTIM]:}

PROSECUTOR: Could you please tell the court your name and age?

MARY ANDERSON: Mary Anderson, I'm [thirteen/six] .

PROSECUTOR: What grade does that put you in at school Mary?

MARY ANDERSON: [Seventh/First].

PROSECUTOR: Can you tell me what you were doing on the afternoon of May 30, 2009 around 3:30?

MARY ANDERSON: Walking home from school.

PROSECUTOR: Where were you walking Mary?

MARY ANDERSON: Through the park. 
PROSECUTOR: What park were you walking through?

MARY ANDERSON: Oak Hill.

PROSECUTOR: What happened when you walked through the park?

MARY ANDERSON: I was walking and looking at the pretty flowers and then saw this man who was walking toward me. He said hi and I said hi back and he said he liked my new shoes. I said thank you and he said he wanted to look at them closer. When I stopped walking he grabbed my arm.

PROSECUTOR: What happened then Mary?

MARY ANDERSON: He pulled me behind the bushes and told me not to make any noise or else he'd hit me.

PROSECUTOR: What happened when he pulled you behind the bushes?

MARY ANDERSON: I told him he was hurting me. I couldn't get away. He said, he said he would hurt me even more if I screamed. He said I was bad.

PROSECUTOR: Then what happened Mary?

MARY ANDERSON: (Crying/Not Crying). He pushed me down on the ground real hard. He grabbed my hair and pushed my face down on the sidewalk. I remember I bit my tongue and it hurt really bad. I closed my eyes. Then he, he jerked my backpack right off me.

PROSECUTOR: What happened after he took your backpack?

MARY ANDERSON: (Crying/Not Crying). He had to let go of my arm and my hair. He said not to move, but when he was looking through my backpack I got up and ran away really fast.

PROSECUTOR: Where did you run to Mary?

MARY ANDERSON: TO my house.

PROSECUTOR: What did you do once you got to your house?

MARY ANDERSON: I told my Mom.

PROSECUTOR: Then what happened?

MARY ANDERSON: My mom called the police and they came to my house and I told them what happened. They said they would let us know when they caught the man.

PROSECUTOR: And did the police call you back? 
MARY ANDERSON: Ya. They called my mom two days later and we went to the police station.

PROSECUTOR: Can you tell me what you did at the police station? MARY ANDERSON: I went into a room with a window and they showed me a bunch of people and asked if the man was one of the people.

PROSECUTOR: And was the man who attacked you in the room Mary?

MARY ANDERSON: Yes.

PROSECUTOR: Is that man in court today?

MARY ANDERSON: Yes.

PROSECUTOR: Can you point him out to me please?

MARY ANDERSON: (Crying/Not Crying). It was him.

PROSECUTOR: Let the record show that the witness has identified the defendant Richard Martins as the assailant. Mary, why are you so sure that this is the man?

MARY ANDERSON: Because it is. I'll never forget him.

PROSECUTOR: What was in your backpack Mary?

MARY ANDERSON: All my stuff. I had my brand new ipod, my school stuff. I had fifty dollars for a field trip that I was supposed to give my teacher, but I forgot. The necklace my grandma gave me with the real pearl on it was in there because it had broke at school that day. I had all my important stuff in there.

PROSECUTOR: Thank you Mary.

\section{CROSS EXAMINATION OF MARY ANDERSON}

DEFENSE ATTORNEY: Mary do you always walk home from school alone? MARY ANDERSON: Unless it's real rainy or something and then my Mom gets me in the car.

DEFENSE ATTORNEY: Do you usually walk through the park?

MARY ANDERSON: NO.

DEFENSE ATTORNEY: Why is that Mary?

MARY ANDERSON: Because I'm not supposed to. 
DEFENSE ATTORNEY: Why are you not supposed to walk through the park?

MARY ANDERSON: Because my Mom and the teachers at school say it isn't safe there.

DEFENSE ATTORNEY: Why did you decide to walk through the park on May 30 th?

MARY ANDERSON: I don't know.

DEFENSE ATTORNEY: Mary were you running late on May 30, 2009 ?

MARY ANDERSON: I don't know.

DEFENSE ATTORNEY: Didn't you tell Officer Young that you had stayed late at school and that you had wanted to get home before your favorite T.V. show?

MARY ANDERSON: Ya, I guess.

DEFENSE ATTORNEY: So were you running late on May 30th?

MARY ANDERSON: Yes.

DEFENSE ATTORNEY: Is it possible Mary that you were in such a hurry that you really didn't get a good look at the man who pushed you down?

MARY ANDERSON: No. I saw him. He grabbed me and pushed me down, I saw him real good.

DEFENSE ATTORNEY: Mary did you scream when the man grabbed your arm?

MARY ANDERSON: No.

DEFENSE ATTORNEY: It must have been very scary. Why didn't you make any noise?

MARY ANDERSON: (Crying/Not Crying). Because he said he would really hurt me if I said anything.

DEFENSE ATTORNEY: I heard you say that you tried to close your eyes when the man grabbed you. Is that true?

MARY ANDERSON: Yes.

DEFENSE ATTORNEY: Well Mary if you were closing your eyes how did you get such a good look at the man? 
MARY ANDERSON: I saw him when he asked about my shoes, and when I got away I saw him real good.

DEFENSE ATTORNEY: Could you be mistaken about who the man is? Maybe Mr. Martins is not the man who assaulted you Mary?

MARY ANDERSON: No. That's him. I know that's him.

DEFENSE ATTORNEY: No more questions your honor.

\section{Appendix C}

Please make sure you answer each question and only mark one answer per question.

If you were a juror on this case, would you find Richard Martins (the defendant): Guilty Not Guilty

\section{How confident are you in this decision? (Please Circle)}

Not at all

1
Somewhat Confident

3
Completely Confident

4 
If guilty, please indicate the number of years Richard Martins (the defendant) should be sentenced (for the crime of aggravated robbery, the minimum sentence is 1 year and the maximum sentence is 25 years):

Years

Please rate how credible Mary Anderson (the victim) was.

Not at all

Somewhat Credible

Very Credible

1

2

3

4

5

Please rate how honest Mary Anderson (the victim) was.

Not at all

Somewhat Honest

Very Honest

1

2

3

4

5

Please rate how good Mary Anderson's (the victim) memory of the event was.

Very Poor

OK

Very Good

1

2

3

4

5

Please rate how likeable Mary Anderson (the victim) was.

Not at all

Somewhat Likeable

Very Likeable

1

2

3

4

5

Please rate Mary Anderson's (the victim) confidence while testifying.

Not at all

Somewhat Confident

Very Confident

1

2

3

4

5

Please rate the accuracy of Mary Anderson's (the victim) testimony.

Not at all

1
Somewhat Credible

3
Very Credible

4

5

Please rate how believable Mary Anderson (the victim) was.

Not at all

Somewhat Believable

Very Believable

1

2

3

4

5

Please rate how calm Mary Anderson (the victim) was.

Not at all

Somewhat Calm

Very Calm

1

2

3

4 
How much blame should be attributed to Mary Anderson (the victim) for the alleged event? $\%$

Please explain why you gave the rating above.

Please describe the behavior of the witness while she was testifying:

\section{Please mark that which best describes you.}

Gender:

Male

$\square$ Female

Race:

African-American

Asian-American

Hispanic

$\square$ Caucasian

$\square$ Other

Age:

\section{Appendix D}

Thank you for your participation in this experiment. As was mentioned in the beginning of the study, this experiment concerns jury decision-making. We are interested in the effect of a child witness's testimony, paired with different behaviors, on jurors' perceptions of witness credibility and verdict decision-making.

Since you participated in our study, you will be given class credit. Please do not discuss this experiment with anyone else who may be a future participant. If they know the purpose of 
the study, it may change how they respond to the materials and the quality of our data will be affected. Thank you for not discussing this experiment with anyone else.

If you have any questions about the experiment, please feel free to ask me now or contact me via email. If you do not have any questions, you are free to go. Thank you again for your participation. 